NJE Vol. 35: 111-120, 2019

Nigerian Journal of Entomology

Published by the Entomological Soc. of Nig.

www.esnjournal.com.ng

DOI.10.36108/NJE/9102/53.01.01

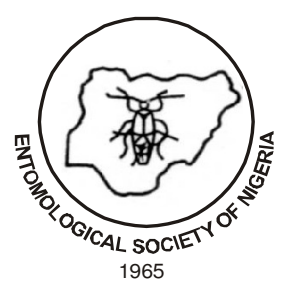

\title{
Efficacy of Selected Beauveria and Metarhizium Isolates Against the Common House Fly, Musca domestica L. [Diptera: Muscidae]
}

\author{
Oyerinde, R. M., Soyelu, O. J.* and Odu, B. O. \\ Department of Crop Production and Protection, Obafemi Awolowo University, \\ Ile-Ife 220005, Osun State, Nigeria
}

\begin{abstract}
The virulence of two Beauveria bassiana (Balsamo-Crivelli) Vuillemin and two Metarhizium spp. (Sorokin) isolates against larval and adult house fly, Musca domestica L. (Diptera: Muscidae), was assessed in the laboratory. Virulence varied significantly among the isolates but insect mortality was independent of route of exposure. Mortality was dose-dependent and stock solutions effected 79-91\% and $63-70 \%$ mortality within seven days in larval and adult house fly, respectively. Generally, the fungi were more virulent against larvae than adult flies and they all showed good potential as effective biocontrol agents. However, consistently lower median lethal concentration $\left(\mathrm{LC}_{50}\right)$ and lethal time $\left(\mathrm{LT}_{50}\right)$ against larval and adult flies showed that $M$. anisopliae s.s. ARSEF 5471 was the most virulent of the four.
\end{abstract}

Keywords: Beauveria bassiana, Biological control, Entomopathogen, Metarhizium spp., Mortality, Musca domestica, Virulence.

\section{INTRODUCTION}

The house fly, Musca domestica L. (Diptera: Muscidae), is a cosmopolitan insect species that has followed man over the centuries; constantly constituting a nuisance especially where livestock are kept and garbage accumulate. Medically, the dipteran affects livestock performance, causes irritation to human beings and possesses a considerable

*Correspondence email:

jlekan2001@yahoo.co.uk potential for mechanical transmission of pathogens (Scott et al., 2000). It was recently found to be a potential carrier of bird flu virus which is a global threat to man, poultry and livestock industry (Iqbal et al., 2014). The control of house fly populations is heavily reliant on the use of chemical insecticides in both spray and bait formulations (Baker et al., 2018). However, the development of resistance to most insecticides by house fly has increased the willingness of researchers to seek alternative methods for fly management (Scott et al., 2000; Kaufman et al., 2005). 
Mycoinsecticide formulations based on entomopathogenic fungi provide a more user and environmentally friendly alternative to conventional chemical insecticides (Lecouna et al., 2005; Mwamburi et al., 2010; AlOlayan, 2013).

Entomopathogenic fungi are promising biological control agents of insect pests (Butt and Goettel, 2000) and they do not need to be ingested to cause infection; mere contact with the pests followed by direct penetration of the cuticle is sufficient (Wright et al., 2002). Entomophthora muscae (Cohn) Fresenius has been used extensively for fly control (Geden et al., 1993; Steinkraus et al., 1993) but its efficacy is limited by shortlived conidia, intolerance to high temperatures and requirement for large populations of flies to sustain epizootics (Geden et al., 1995). The broad host range of Beauveria bassiana (Balsamo) Vuillemin and some Metarhizium strains is an indication of the potential of these pathogenic fungi as biological control agents (Humber, 2014). Steinkraus et al. (1990) and Geden et al. (1995) reported natural infection of house flies by $B$. bassiana suggesting that the pathogen is compatible with environmental conditions in different agroecosystems (Watson et al., 1995, 1996; Kaufman et al., 2005). Compared to $E$. muscae, B. bassiana is a more promising biological control agent of house fly because it is easily and economically produced, its conidia have a longer storage life, and it can be formulated and applied in a variety of ways (Feng et al., 1994; Humber, 2014).

Studies have shown that susceptibility of insects to fungal pathogens varies with the developmental stage (Ekesi and Maniania, 2000; Lecuona et al., 2005; Mwamburi et al., 2010) and understanding which stage is most susceptible to infection is important for the development of species-specific management tactics (Ferron, 1985). This study was, therefore, carried out to compare the susceptibility of larval and adult stages of $M$. domestica to infection by selected Beauveria and Metarhizium strains; and identify highly virulent fungal strain that could be used in the development of mycoinsecticides.

\section{MATERIALS AND METHODS}

\section{Acquisition, reactivation and plating of fungal isolates}

Four fungal isolates (Table 1) were obtained from the USDA-ARS Biological Integrated Pest Management Research Unit, New York, USA in lyophilized form inside flame-sealed ampules and rubber-capped serum bottles. The pathogens were reactivated at the Germplasm and Health Laboratory, International Institute of Tropical Agriculture (IITA), Ibadan, Nigeria. Each ampule was broken with tissue paper, dampened in $70 \%$ ethanol, carefully held against the surface for the purpose of disinfection. Sterile distilled water $(0.5 \mathrm{ml})$ was added aseptically and the content was aspirated gently using a sterile pipette. The suspension was left undisturbed for $30 \mathrm{~min}$ after which it was inoculated on Potato Dextrose Agar (PDA).

\section{Establishment of fungal cultures and preparation of inoculum}

Fungal isolates were sub-cultured from a week-old PDA plates at the Pathology Preparatory Room, Department of Crop Production and Protection, Obafemi Awolowo University, Ile-Ife. Potato Dextrose Agar (1000 ml) was prepared by autoclaving $20 \mathrm{~g}$ powdered agar in distilled water. Lactic acid (25\%) was added to the autoclaved mixture at the point of pouring into $9 \mathrm{~cm}$-diameter Petri dishes in order to reduce the $\mathrm{pH}$ level. A cutting knife, sterilized in $70 \%$ ethanol and flamed over a spirit lamp, was used in cutting and plating each fungal isolate. The sterilizing procedure was repeated before each isolate was cut and 
plating was done in a transfer chamber under aseptic condition. The prepared plates were incubated at $27^{\circ} \mathrm{C}$ for 7 days at the end of which sporulating cultures were harvested by scraping dry conidia with a scalpel and washing them with distilled water into sterile vials. Concentration (conidia/ml) of each stock solution was determined using a haemocytometer and serial dilutions were made (Table 2).

\section{Rearing of house fly}

Adult house flies were collected from dumpsites within Obafemi Awolowo University, Ile-Ife, and they were reared in laboratory cages at $27^{\circ} \mathrm{C}, 45 \pm 5 \% \mathrm{RH}$ and 12:12 light: dark photoperiod. The flies were provided with sugar cubes and water was supplied in soaked cotton wool balls. Larvae were reared on a moistened artificial diet of blended rice (carbohydrate) and fish (protein) in ratio $4: 1(\mathrm{w} / \mathrm{w})$ as recommended by Cooper et al. (2004). Food sources were renewed frequently to prevent fungal growth in the cages. Rearing cages were monitored daily and pupae were transferred into separate cages for adult emergence. The rearing procedure was repeated and third generation larval and adult flies were selected for bioassays.

\section{Mortality test by dipping (dermal toxicity)}

Ten 3rd instar larvae were dipped in the stock solution of each fungal isolate for $10 \mathrm{~s}$. An equal number of larvae was also dipped, for the same period, in each serial concentration per isolate. In each case, dipping was done in triplicate and larvae dipped in distilled water served for comparison of results. After dipping, each larval group was placed on damp filter paper inside perforated plastic bowl. The blended rice and fish diet was supplied and each bowl was covered with white gauze held in place with rubber band. Each larval group was monitored and mortality was recorded daily for 7 days. Newly emerged (3-4 days old) adult flies were also treated in a manner similar to that described for larvae and mortality was recorded daily for 7 days. Dead insects were removed as soon as possible, prior to sporulation, to prevent cross infection. The dead specimens were kept in labelled plastic bowls lined with moistened filter paper and monitored for evidence of mycotic symptoms.

\section{Mortality test by ingestion (oral toxicity)}

Artificial diet sprayed with conidial suspensions (i.e. stock, serial dilutions) of each fungal strain was fed to $3^{\text {rd }}$ instar house fly larvae in triplicated groups of ten larvae. The control experiment consisted of larvae that were provided with untreated diet. The larval groups were enclosed in separate perforated plastic bowls which were arranged in completely randomized design. The bowls were monitored and larval mortality was recorded daily for 7 days. Test and control experiments were also set up for adult flies in $35 \times 35 \times 35 \mathrm{~cm}^{3}$ rearing cages. Groups of 3 4 days old adult flies, in separate cages, were provided with a mixture of sugar and conidial suspension. Control flies were provided with sugar solution alone; the cages were monitored and adult mortality was recorded daily for 7 days.

\section{Confirmation of fungal infection in dead house flies}

Dead house flies collected from each experimental group were rinsed in distilled water to harvest the conidia and serial dilution was done to reduce the inoculum load. The obtained suspension was then cultured on PDA for 5 days. Resulting fungal growth was sub-cultured subsequently till a less clustered culture was obtained. Harvested conidia were suspended in $1 \mathrm{ml}$ sterile water containing $0.05 \%$ (vol/vol) 
Tween ${ }^{\circledR} 20$ (Promega Corporation, Madison, WI) and Trypan blue was added to make the fungal spores more conspicuous under the compound microscope. Morphological characters were compared between the obtained culture and original pure culture from ARSEF collection using identification keys provided for $B$. bassiana and Metarhizium spp. (Humber, 1997).

\section{Statistical analysis}

The generated mortality data were square root-transformed before being subjected to combined and intra-isolate analyses of variance (ANOVA) to determine statistical significance and percent contribution of each source of variation to house fly mortality. Mean values were separated using Tukey's HSD at $\alpha_{0.05}$ (SAS Institute, 2002). The median lethal concentration $\left(\mathrm{LC}_{50}\right)$ and lethal time $\left(\mathrm{LT}_{50}\right)$ were estimated from mortality data by Probit analysis using the Polo-Plus for Windows v. 2.0 program (LeOra Software, Petaluma, CA).

\section{Mortality test}

\section{RESULTS}

The combined analysis of variance on virulence of the four entomopathogenic fungal isolates against $M$. domestica is presented in Table 3. Mortality varied significantly $(\mathrm{P}<0.001)$ with fungal isolate, concentration of inoculum, stage of house fly inoculated and number of days after inoculation. However, method of inoculation (dipping or ingestion) did not have any significant effect $(\mathrm{P}>0.05)$ on house fly mortality. The concentration of inoculum contributed over $50 \%$ of variation in mortality followed by the number of days post-inoculation $(25 \%)$. The interaction between these two sources of variation also contributed a substantial proportion $(8 \%)$ to variation in mortality. Intra-isolate analyses of variance for ARSEFs 1564, 1057 and
5471 showed a trend similar to the one reported for combined analysis with respect to significance and percent contribution of sources of variation to house fly mortality. On the contrary, contribution of inoculum concentration to house fly mortality $(22 \%)$ was lower than that of number of days postinoculation $(55 \%)$ in the case of ARSEF 8891 (Table 4).

The fungal efficacy against larval and adult house fly over a period of 7 days is presented in Table 5. The fungi showed good insecticidal potential against larval stage, producing $79.3-90.7 \%, 72.6-85.0 \%$, 61.7$76.0 \%$ and $52.6-69.5 \%$ mortality with the stock solution and three successive serial concentrations, respectively. However, ARSEF 1057 ( $M$. robertsii) had a consistently lower efficacy against the larvae. There was a significant reduction in fungal efficacy against adults with only the stock solution and its $10 \%$ dilution achieving at least $50 \%$ insect mortality within seven days of inoculation. Obtained mortality ranged from $63.3-70.0 \%$ for stock solution; and $50.2-56.7 \%, 42.6-48.8 \%$ and $31.7-42.1 \%$ for successive serial concentrations, respectively. Interestingly, the performance of ARSEF 1057 compared very well with those of other three isolates. Generally, house fly mortality was concentrationdependent and there was no mortality among larval and adult house flies treated with distilled water in control experiments.

\section{Median lethal concentration $\left(\mathrm{LC}_{50}\right)$ and time $\left(\mathbf{L T}_{\mathbf{5 0}}\right)$}

The 24-h median lethal concentration $\left(\mathrm{LC}_{50}\right)$ and number of days $\left(\mathrm{LT}_{50}\right)$ taken by each entomopathogenic fungus to kill $50 \%$ of the initial larval and adult house fly populations are presented in Table 6 . For oral and dermal toxicity, each fungus had lower $\mathrm{LC}_{50}$ values against the larvae compared to adult house flies. However, M. anisopliae s.s. (ARSEF 
5471) had consistently lower $\mathrm{LC}_{50}$ values compared to the other three isolates. Irrespective of the method of inoculation, it took a shorter time for each fungal isolate to eliminate inoculated larvae compared to adults. Generally, ARSEF 5471 eliminated $50 \%$ of the initial populations faster than other fungal isolates; by as much as $1.5 \mathrm{~d}$ in the case of larval dermal toxicity.

\section{Confirmation of fungal infection in dead house flies}

The fungal colonies that developed from dead house flies had characters that were consistent with those of the ARSEF pathogens they were infected with.

Beauveria bassiana: Fungal colonies were usually slow-growing and appeared powdery, not exceeding $2 \mathrm{~cm}$ in ten days at $25{ }^{\circ} \mathrm{C}$; white at first but later became pale yellow. The hyphae and spores were nonpigmented (hyaline) and conidia were subglobose to globose. The conidiophores did not form synnemata and conidia (one per denticle) were produced sympodially in acropetal succession on elongating conidiogenous cells. The conidiogenous cells were densely clustered and had globose bases with denticulate apical extensions, a key characteristic of B. bassiana.

Metarhizium: Conidiogenous cells are borne at apices of broadly branched, densely intertwined conidiophores that form a compact hymenium; conidia borne in parallel chains and green in mass. Conidiogenous cells aseptate, short, without apical necks; conidia cylindrical, forming long chains that adhere laterally to create a solid mass of parallel chains. Conidiophores branching repeatedly at broad angles and resembling a candleholder (Metarhizium anisopliae); conidiogenous cell cylindrical; conidia cylindrical and with a slight central narrowing ( $M$. robertsii).

Table 1: The extracted details of four entomopathogenic fungal isolates used in the study

\begin{tabular}{|c|c|c|c|c|c|}
\hline Scientific name & $\begin{array}{l}\text { Accession } \\
\text { number }\end{array}$ & $\begin{array}{l}\text { Depositor and } \\
\text { depositor's } \\
\text { reference } \\
\text { number }\end{array}$ & Original host & $\begin{array}{l}\text { Date of } \\
\text { accession or } \\
\text { receipt by } \\
\text { ARSEF }\end{array}$ & $\begin{array}{l}\text { Country of } \\
\text { origin }\end{array}$ \\
\hline $\begin{array}{l}\text { Beauveria } \\
\text { bassiana }\end{array}$ & ARSEF 1564 & $\begin{array}{l}\text { K.V. Deseö } \\
(103)\end{array}$ & $\begin{array}{l}\text { Hyphantria cunea } \\
\text { (Lepidoptera: } \\
\text { Arctiidae) }\end{array}$ & March 1984 & $\begin{array}{l}\text { Emilia- } \\
\text { Romagna, Italy }\end{array}$ \\
\hline B. bassiana & ARSEF 8891 & Anonymous & $\begin{array}{l}\text { Danaus plexippus } \\
\text { (Lepidoptera: } \\
\text { Danaidae) }\end{array}$ & $\begin{array}{l}\text { October } 11, \\
1984\end{array}$ & $\begin{array}{l}\text { Queensland, } \\
\text { Australia }\end{array}$ \\
\hline $\begin{array}{l}\text { Metarhizium } \\
\text { robertsii }\end{array}$ & ARSEF 1057 & F. Moscardi & $\begin{array}{l}\text { Chlosyne lacinia } \\
\text { saundersii } \\
\text { (Lepidoptera: } \\
\text { Nymphalidae) }\end{array}$ & 1983 & Paraná, Brazil \\
\hline $\begin{array}{l}\text { M. anisopliae } \\
\text { s.s. }\end{array}$ & ARSEF 5471 & $\begin{array}{l}\text { T.J. Poprawski } \\
\text { (TJP936) }\end{array}$ & $\begin{array}{l}\text { Eoreuma loftini } \\
\text { (Lepidoptera: } \\
\text { Pyralidae) }\end{array}$ & May 9, 1997 & Texas, USA \\
\hline
\end{tabular}

Source: Humber (2014). 
Table 2: Stock and serial concentrations of each entomopathogenic fungal isolate used in inoculating Musca domestica

\begin{tabular}{|c|c|c|c|c|c|}
\hline \multirow[t]{3}{*}{ Fungal isolate } & \multirow[t]{3}{*}{ Accession number } & \multicolumn{4}{|c|}{ Concentration of inoculum (conidia/ml) } \\
\hline & & \multirow[t]{2}{*}{ Stock solution } & \multicolumn{3}{|c|}{ Serial concentration (SC) } \\
\hline & & & SC 1 & SC 2 & SC 3 \\
\hline Beauveria bassiana & ARSEF 1564 & $1.70 \times 10^{7}$ & $1.70 \times 10^{6}$ & $1.70 \times 10^{5}$ & $1.70 \times 10^{4}$ \\
\hline B. bassiana & ARSEF 8891 & $3.20 \times 10^{7}$ & $3.20 \times 10^{6}$ & $3.20 \times 10^{5}$ & $3.20 \times 10^{4}$ \\
\hline Metarhizium robertsii & ARSEF 1057 & $2.10 \times 10^{7}$ & $2.10 \times 10^{6}$ & $2.10 \times 10^{5}$ & $2.10 \times 10^{4}$ \\
\hline M. anisopliae s.s. & ARSEF 5471 & $0.848 \times 10^{7}$ & $0.848 \times 10^{6}$ & $0.848 \times 10^{5}$ & $0.848 \times 10^{4}$ \\
\hline
\end{tabular}

Table 3: Significance and percent contribution of each source of variation to mortality in Musca domestica using four entomopathogenic fungi

\begin{tabular}{llll}
\hline Source of variation $(\mathrm{SV})$ & Df & Mean square & Contribution $(\%)$ \\
\hline Concentration of inoculum & 4 & $3536.71 * * *$ & 54.11 \\
Day after inoculation & 6 & $1099.72^{* * *}$ & 25.24 \\
Stage of house fly inoculated & 1 & $944.73 * * *$ & 3.61 \\
Fungal isolate & 3 & $15.27 * * *$ & 0.18 \\
Method of inoculation & 1 & 0.01 & $3.14 \times 10^{-5}$ \\
Replicate & 2 & 1.34 & $1.02 \times 10^{-2}$ \\
Error & 1388 & 0.81 & 4.29 \\
$\mathrm{R}^{2}$ & & 0.957 & \\
Coefficient of Variability & & 15.27 & \\
\hline
\end{tabular}

*** Significance at 0.001 level of probability.

The analyses of variance included first and second order interactions among main sources of variation but only the main effects are presented in the Tables. Percent contributions of 1 st and 2nd order interactions to house fly mortality ranged between $3.28 \times 10-4 \%$ (Method of inoculation $\times$ Stage of house fly inoculated, $\mathrm{P}>0.05$ ) and $8.09 \%$ (Day after inoculation $\times$ Concentration of inoculum, $\mathrm{P}<0.001$ ).

Table 4: Mean square value and percent contribution of each source of variation to house fly mortality due to ARSEF 8891 infection

\begin{tabular}{llll}
\hline Source of variation $(\mathrm{SV})$ & Df & Mean square & Contribution $(\%)$ \\
\hline Concentration of inoculum & 4 & $250.75^{* * *}$ & 22.49 \\
Day after inoculation & 6 & $914.27^{* * *}$ & 54.66 \\
Stage of house fly inoculated & 1 & $367.86^{* * *}$ & 5.50 \\
Method of inoculation & 1 & 0.00 & $7.77 \times 10^{-7}$ \\
Replicate & 2 & 0.77 & 0.022 \\
Error & 302 & & \\
$\mathrm{R}^{2}$ & 95.19 & & \\
Coefficient of Variability & 17.55 & & \\
\hline
\end{tabular}

*** Significance at 0.001 level of probability.

Percent contribution of 1 st and 2 nd order interactions to house fly mortality ranged between $0.10 \%$ (Method of inoculation $\times$ Stage of house fly inoculated, $\mathrm{P}<0.001$ ) and $7.94 \%$ (Day after inoculation $\times$ Concentration of inoculum, $\mathrm{P}<0.001$ ). 
Table 5: Insecticidal efficacy of four entomopathogenic fungal isolates against larval (A) and adult (B) stages of Musca domestica within seven days of inoculation

\begin{tabular}{|c|c|c|c|c|c|c|c|c|c|}
\hline A & \multicolumn{4}{|c|}{ Percent mortality over a period of 7 days } & B & \multicolumn{4}{|c|}{ Percent mortality over a period of 7 days } \\
\hline TRT & $\begin{array}{c}\text { ARSEF } \\
1564\end{array}$ & $\begin{array}{c}\text { ARSEF } \\
8891\end{array}$ & $\begin{array}{c}\text { ARSEF } \\
1057\end{array}$ & $\begin{array}{c}\text { ARSEF } \\
5471\end{array}$ & TRT & $\begin{array}{c}\text { ARSEF } \\
1564\end{array}$ & $\begin{array}{c}\text { ARSEF } \\
8891\end{array}$ & $\begin{array}{c}\text { ARSEF } \\
1057\end{array}$ & $\begin{array}{c}\text { ARSEF } \\
5471\end{array}$ \\
\hline Stock & $86.91^{\text {ab }}$ & $90.71^{\mathrm{a}}$ & $79.29^{b}$ & $87.14^{\mathrm{ab}}$ & Stock & $63.33^{\mathrm{a}}$ & $70.00^{\mathrm{a}}$ & $68.57^{\mathrm{a}}$ & $68.57^{\mathrm{a}}$ \\
\hline $\mathrm{SC} 1$ & $76.67^{\mathrm{bc}}$ & $81.91^{\mathrm{ab}}$ & $72.62^{\mathrm{c}}$ & $85.00^{\mathrm{a}}$ & $\mathrm{SC} 1$ & $50.24^{\mathrm{b}}$ & $52.86^{\mathrm{ab}}$ & $56.67^{\mathrm{a}}$ & $56.19^{\mathrm{ab}}$ \\
\hline SC 2 & $69.05^{\mathrm{a}}$ & $70.48^{\mathrm{a}}$ & $61.67^{\mathrm{b}}$ & $75.95^{\mathrm{a}}$ & SC 2 & $42.62^{\mathrm{a}}$ & $46.19^{\mathrm{a}}$ & $46.43^{\mathrm{a}}$ & $48.81^{\mathrm{a}}$ \\
\hline $\mathrm{SC} 3$ & $60.00^{\mathrm{b}}$ & $66.67^{\mathrm{a}}$ & $52.62^{\mathrm{c}}$ & $69.52^{\mathrm{a}}$ & $\mathrm{SC} 3$ & $36.19^{\mathrm{a}}$ & $31.67^{\mathrm{b}}$ & $38.81^{\mathrm{a}}$ & $42.14^{\mathrm{a}}$ \\
\hline $\begin{array}{l}\text { Contr } \\
\text { ol }\end{array}$ & $0.00^{\mathrm{a}}$ & $0.00^{\mathrm{a}}$ & $0.00^{\mathrm{a}}$ & $0.00^{\mathrm{a}}$ & Control & $0.00^{\mathrm{a}}$ & $0.00^{\mathrm{a}}$ & $0.00^{\mathrm{a}}$ & $0.00^{\mathrm{a}}$ \\
\hline
\end{tabular}

Values with similar alphabets within the same row are not significantly different at 0.05 level of probability. ARSEFs 1564 and 8891: Beauveria bassiana; ARSEF 1057: Metarhizium robertsii; and ARSEF 5471: M. anisopliae s.s. TRT: Treatment; SC: Serial concentration

Table 6: Median lethal concentration $\left(\mathrm{LC}_{50}\right)$ and lethal time $\left(\mathrm{LT}_{50}\right)$ of four entomopathogenic fungi against larval and adult house fly, Musca domestica

\begin{tabular}{|c|c|c|c|c|c|c|c|c|}
\hline \multirow[t]{3}{*}{ Isolate } & \multicolumn{4}{|c|}{$\mathrm{LC}_{50}\left(\times 10^{4}\right.$ conidial ml $\left.{ }^{-1}\right)$} & \multicolumn{4}{|c|}{$\mathrm{LT}_{50}$ (day) } \\
\hline & \multicolumn{2}{|c|}{ Oral toxicity } & \multicolumn{2}{|c|}{ Dermal toxicity } & \multicolumn{2}{|c|}{ Oral toxicity } & \multicolumn{2}{|c|}{ Dermal toxicity } \\
\hline & Larva & Adult & Larva & Adult & Larva & Adult & Larva & Adult \\
\hline $\begin{array}{l}\text { ARSEF } \\
1564\end{array}$ & 1997.82 & 5063.35 & 997.11 & 6783.64 & 3.43 & 4.74 & 3.04 & 4.99 \\
\hline $\begin{array}{l}\text { ARSEF } \\
8891\end{array}$ & 2486.91 & 5397.15 & 2289.38 & 13347.56 & 3.17 & 4.84 & 2.82 & 4.65 \\
\hline $\begin{array}{l}\text { ARSEF } \\
1057\end{array}$ & 1746.13 & 7057.90 & 1987.32 & 3652.69 & 3.43 & 4.76 & 4.01 & 4.43 \\
\hline $\begin{array}{l}\text { ARSEF } \\
5471\end{array}$ & 768.26 & 2775.07 & 420.01 & 2088.01 & 3.14 & 4.38 & 2.56 & 4.09 \\
\hline
\end{tabular}

ARSEFs 1564 and 8891: Beauveria bassiana; ARSEF 1057: Metarhizium robertsii; ARSEF 5471: M. anisopliae s.s.

\section{DISCUSSION}

A number of entomopathogenic fungi have been isolated from house fly but none of the four tested in this study came from the dipteran. The isolates were originally suggested by Dr. Richard Humber (USDAARS, New York) against Acraea eponina (Cramer) which is a major nymphalid pest of the jute mallow, Corchorus olitorius L, in Nigeria. However, the initial study could not be carried out and we decided to test the isolates on house fly. A search through the
11,802 isolates in ARSEF catalog (Humber, 2014) showed that unlike $B$. bassiana, Metarhizium spp. have not been isolated from house fly. Despite this, the experiments clearly demonstrated that all fungal strains tested, especially M. anisopliae s.s. ARSEF 5471, can be effective biological control agents against $M$. domestica.

Pathogenicity of the four fungal isolates against larval and adult house fly was determined largely by concentration of inoculum applied and stock conidial 
suspensions gave highest mortality. This positive correlation between concentration of conidial suspension and insect mortality abounds in literature (e.g., Watson et al., 1995; Devi and Rao, 2006; Santoro et al., 2008; Mwamburi et al., 2010). The rate of enzymatic degradation of the cuticle and generated physical pressure needed to penetrate the integument, the rate at which organs are invaded, the rate at which fungal toxins are accumulated and, ultimately, death may be dependent on conidial population in the inoculum. Since insecticidal efficacy did not vary significantly with Method of inoculation (i.e. dermal or oral route), ensuing mycoinsecticide(s) could be in form of body sprays or food baits. This gives room for selecting a formulation that is cheaper, more convenient to use and more stable in storage. However, Butt and Goettel (2000) stated that most hosts are infected through the cuticle while infection through the digestive tract occurs in few insect species.

The tested fungal isolates were more virulent against larval house fly than adults; an account that ran contrary to the report of Mwamburi et al. (2010) in which all thirtyfour isolates of $B$. bassiana applied were more effective against adult house fly than larvae. There have been a lot of mixed results with respect to the stage of insect pests that is most susceptible to fungal infection. For example, the susceptibility of whiteflies to Aschersonia aleyrodis Webber decreased with age, the early stages being more susceptible to infection than the late stages (Fransen et al., 1987), whereas the early stages of Helicoverpa spp. have been reported to be less susceptible to Nomuraea rileyi (Farlow) Samson compared to later stages (Mohamed et al., 1977). Ekesi and Maniania (2000) reported higher susceptibility in adult legume flower thrips, Megalurothrips sjostedti Trybom (Thysanoptera: Thripidae), to $M$. anisopliae compared to the larval and pupal stages. These differences in outcomes may be the result of differences in characteristics of fungal strains and insect pest species involved in each case. In addition, the insect cuticle acts as a barrier to fungal penetration and its thickness increases with every moult so that differences in susceptibility to entomopathogenic fungi can be explained by insect cuticular properties (Boucias and Pendland, 1991), with younger individuals being more susceptible than older ones. Selection of a virulent organism that is more active against the most destructive stage of a crop pest is evidently the desired outcome of microbial control interventions.

The fungal strains applied in this study showed good performance against house fly, and the median lethal values $\left(\mathrm{LC}_{50}\right.$ and $\left.\mathrm{LT}_{50}\right)$ revealed M. anisopliae s.s. ARSEF 5471 as the most virulent. This was evident in the lesser conidial concentration and fewer number of days it needed to kill half of the initial house fly population compared to other three isolates. Although mycotic symptoms and insect mortality were first recorded among house flies treated with $B$. bassiana ARSEF 8891, M. anisopliae eventually outperformed it. Differences in isolate virulence may be attributed to one of two main strategies; an isolate may produce a large amount of toxins or it may focus its energy on vegetative growth (Al-Olayan, 2013). It may be that ARSEF 8891 partitioned more biological resources to vegetative growth rather than production of toxins which are needed to suppress the immune system and ultimately cause death in insects.

This study has succeeded in identifying additional entomopathogenic fungi with promising efficacy against larval and adult house fly. All fungal strains tested in the laboratory are potential candidates for further development as biological control agents and 
success in this regard would lead to a significant reduction in dependency on synthetic chemicals for the control of house fly.

\section{ACKNOWLEDGEMENTS}

The authors are grateful to the U.S. Department of Agriculture and ARS Plant Protection Research Unit for providing the Beauveria bassiana (ARSEF 1564, ARSEF 8891), Metarhizium robertsii (ARSEF 1057) and Metarhizium anisopliae s.s. (ARSEF 5471) cultures. Dr. Richard A. Humber, Insect Mycologist and Curator of ARSEF, is appreciated for his professional guidance. Messrs Wole Oguntade of IITA, Ibadan and Neddy Osude of the Department of Crop Production and Protection, OAU, Ife are appreciated for reactivating the imported pathogens and establishing fungal cultures in the laboratory.

\section{REFERENCES}

Al-Olayan, E. B. (2013). Evaluation of pathogenicity of certain mitosporic ascomycete fungi to the house fly, Musca domestica L. (Diptera: Muscidae). Journal of Saudi Chemical Society, 17: 97-100.

Baker, D. K., Rice, S. J., Leemon, D. M. and James, P. J. (2018). Horizontal transmission of Metarhizium anisopliae (Hypocreales: Clavicipitacea) and the effects of infection on oviposition rate in laboratory populations of Musca domestica (Diptera: Muscidae). Pest Management Science DOI: 10.1002/ps.4799.

Boucias, D. and Pendland, J. (1991). Attachment of mycopathogens to cuticle. In: The Fungal Spore and Disease Initiation in Plants and Animals (Cole, G. T. and Hoch, H. C. eds.), Plenum Press, New York, pp. 101-127.

Butt, T. M. and Goettel, M. S. (2000). Bioassays of entomogenous fungi. In: Bioassays of Entomopathogenic Microbes and Nematodes (Navon, A. and Ascher, K. R. S. eds.), CAB International, Wallingford, pp. 141-195.
Cooper T. M., Mockett R. J., Sohal B. H., Sohal R. S. and Orr W. C. (2004). Effect of caloric restriction on life span of the housefly Musca domestica. FASEB Journal 18, 1591-1593.

Devi, K. U. and Rao, C. U. M. (2006). Allele effect in the infection dynamics of the entomopathogenic fungus Beauveria bassiana (Bals) Vuill. on the beetle Mylabris pustulata. Mycopathologia 161: 385-394.

Ekesi, S. and Maniania, N. K. (2000). Susceptibility of Megalurothrips sjostedti developmental stages to Metarhizium anisopliae and the effects of infection on feeding, adult fecundity, egg fertility and longevity. Entomologia Experimentalis et Applicata 94: 229-236.

Feng, M. G., Proprawski, T. J. and Khachatourians, G. C. (1994). Production, formulation and application of the entomopathogenic fungus Beauveria bassiana for insect control: current status. Biocontrol Science and Technology 4: 3-34.

Ferron, P. (1985). Fungal control. In: Comparative Insect Physiology, Biochemistry and Pharmacology (Kerkut, G. A. and Gilbert, L. I. eds.), Pergamon Press, Oxford, 12: 313-346.

Fransen, J. J., Winkelman, K. and van Lenteren, J. C. (1987). The differential mortality at various life stages of the greenhouse whitefly, Trialeurodes vaporariorum (Homoptera: Aleyrodidae), by infection with the fungus Aschersonia aleyrodis (Deuteromycotina: Coelomomycetes). Journal of Invertebrate Pathology 50: 158-165.

Geden, C. J., Rutz, D. A. and Steinerkraus, D. C. (1995). Virulence of different isolates and formulation of Beauveria bassiana for house flies and the parasitoid muscidofurax raptor. Journal of Biology Conference 5: 615-621.

Geden, C. J., Steinerkraus, D. C. and Rutz, D. A. (1993). Evaluation of two methods for release of Entomophthora musca (Entomophthorales: Entomophthoraceae) to infect house flies (Diptera: Muscidae) on dairy farms. Journal of Environmental Entomology 20: 1201-1208.

Humber, R. A. (1997). Fungi: Identification. In: Biological Techniques in Invertebrate 
Pathology (Lacey, L. A. ed.), Academic Press, London, pp. 153-185.

Humber, R. A. (2014). USDA-ARS Collection of Entomopathogenic Fungal Cultures ARSEF: Catalog of Strains. U.S. Department of Agriculture, Agricultural Research Service, Washington, D.C. 608pp.

Iqbal, W., Malik, M. F., Sarwar, M. K., Azam, I., Iram, N. and Rashda, A. (2014). Role of housefly (Musca domestica, Diptera; Muscidae) as a disease vector: A review. Journal of Entomology and Zoology Studies 2(2): 159-163.

Kaufman, P. E., Reasor, C., Rutz, D. A., Ketzis, J. K. and Arends, J. (2005). Evaluation of Beauveria bassiana applications against adult house fly, Musca domestica, in commercial caged-layer poultry facilities in New York State. Biological Control 33: 360-367.

Lecuona, R. E., Turica, M., Tarocco, F. and Crespo, D. C. (2005). Microbial control of Musca domestica (Diptea: Muscidae) with selected strains of Beauveria bassiana. Journal of Medical Entomology 42(3): 332336.

Mohamed, A. K. A., Sikorowski, P. P. and Bell, J. V. (1977). Susceptibility of Heliothis zea larvae to Nomuraea rileyi at various temperatures. Journal of Invertebrate Pathology 30: 414-417.

Mwamburi, L. A., Laing, M. D. and Miller, R. M. (2010). Laboratory screening of insecticidal activities of Beauveria bassiana and Paecilomyces lilacinus against larval and adult House Fly (Musca domestica L.). African Entomology 18(1): 38-46.

SAS Institute (2002). SAS/STAT User's Guide Release V9. SAS Institute, Cary, North Carolina.
Santoro, P. H., Neves, P. M. O. J., Alexandre, T. M., Sartori, D., Alves, L. F. A. and Fungaro, M. H. P. (2008). Selection of Beauveria bassiana isolates to control Alphitobius diaperinus. Journal of Invertebrate Pathology 97: 83-90.

Scott, J. G., Alefanti, T. G., Kaufman, P. E. and Rutz, D. A. (2000). Insecticide resistance in house flies from caged layer poultry facilities. Pest Management Science 56: 147-153.

Steinkraus, D. C., Geden, C. J. and Rutz, D. A. (1993). Prevalence of Entomophthora muscae (Cohn) Fresenius (Zygomycetes: Entomophthoraceae) in house flies (Diptera: Muscidae) on dairy farms in New York and induction of epizootics. Biological Control 3: 93-100.

Steinkraus, D. C., Geden, C. J., Rutz, D. A. and Kramer, J. P. (1990). First report of the natural occurrence of Beauveria bassiana (Moniliales: Moniliaceae) in Musca domestica (Diptera: Muscidae). Journal Medical Entomology 27: 309-312.

Watson, D. W., Geden, C. G., Long, S. J. and Rutz, D. A. (1995). Efficacy of Beauveria bassiana for controlling the house fly and stable fly (Diptera: Muscidae). Biological Control 5: 405-411.

Watson, D. W., Rutz, D. A. and Long, S. J. (1996). Beauveria bassiana and sawdust bedding for the management of the house fly, Musca domestica (Diptera: Muscidae) in calf hutches. Journal of Biological Control, 7: 221-227.

Wright, M. S., Osbrink, W. L. A. and Lax, A. R. (2002). Transfer of entomopathogenic fungi among formosan subterranean termites and subsequent mortality. Journal of Applied Entomology, 126: 20-23.
NJE Vol. 35: 111-120, 2019

Nigerian Journal of Entomology

Published by the Entomological Soc. of Nig.

www.esnjournal.com.ng

DOI.10.36108/NJE/9102/53.01.01

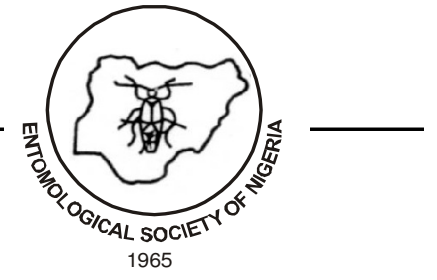

